(C) 1982. The Genetical Society of Great Britain

\title{
CORRECTION
}

\section{THE FREQUENCY OF HETEROZYGOTES MAINTAINED IN SYNTHETIC POPULATIONS OF NICOTIANA RUSTICA: \\ A CORRECTION}

HILARIE J. BOUGHEY, CLAIRE DOUGLAS, M. K. S. AL-BANNA, and J. L. JINKS

The general formula given by Boughey et al. (1981)* for the frequency of heterozygotes, $\beta_{n}$, in the $n$th generation is incorrect. It should be

$$
\beta_{n}=2 u v \sum_{i=1}^{n}(f / 2)^{i-1}(1-f) .
$$

As a consequence the specific equations for $n=2$ and $n=3$ were also incorrect and should be

$$
\beta_{2}=2 u v-u v f-u v f^{2}
$$

and

$$
\beta_{3}=2 u v-u v f-\frac{1}{2} u v f^{2}-\frac{1}{2} u v f^{3} .
$$

The estimates of $\left(1-f_{n}\right)$ in table 2 obtained from these formulae are correct except for $\left(1-f_{n}\right)$ for generation $S_{3}$ in population $B$ which should be 0.2541 instead of 0.2723 and for $S_{2}$ in population $D$ which should be 0.2124 instead of 0.2129 .

None of the conclusions is affected. 